\section{Spat over Gulf War windfall}

\section{Washington}

IN winning the war in the Persian Gulf, US military officials were forced to surrender, at least temporarily, in another dispute - a long-running struggle with researchers over access to satellite data. But now that the war is over, the Department of Defense is threatening once again to take back its data, and the researchers are up in arms.

Early last year, scientists protested when the Department of Defense announced a decision to begin encrypting the signals from its array of Global Positioning System (GPS) satellites. With their ability to give precise Earth coordinates in real time, these satellites have become irreplaceable tools for an increasing number of researchers. Although encrypted signals are still usable for some applications, encryption reduces the position accuracy by almost a factor of ten for anyone who does not have the special receivers that decode the signals. So scientists - including some Japanese seismologists who found themselves suddenly unable to measure crustal movement to predict earthquakes - criticized the decision and sought special access for legitimate research uses (see Nature 345, 195; 17 May 1990).

But the squabble ended abruptly late last year when the researchers discovered that the encryption had been mysteriously turned off. And after a little investigation, they dis- covered the reason: GPS had proved so useful as a navigational aide to the troops that the demand for military receivers (with decryption) quickly outstripped the supply.

The only quick solution was for Allied forces to buy the same commercial receivers that scientists have been using for geological and Earth-observation research - and for the Department of Defense to return GPS to its original open-access status so that the commercial receivers could be used.

Researchers fear, however, that the lifting of the signal encryption may be only temporary. While the military now owns thousands of commercial GPS receivers that would be nearly useless if the encryption - known as selective availability - were turned back on, the war is, after all, over and those receivers are not now needed. Department of Defense officials argue that if they leave the encryption off in peacetime, commercial systems and perhaps even GPS-guided enemy missiles - will proliferate.

"If full GPS accuracy is available to the public ... there will be irresistible pressure to maintain signal accuracy in time of crisis," US Air Force General Donald Kutyna told the Senate Armed Forces Committee last month. "I believe that would place our forces at risk from smart weapons using GPS guidance."

A military review panel has been assem- bled to make recommendations on when and how much GPS distortion should be used in peacetime. The GPS Association, a California-based coalition of GPS receiver manufacturers, is lobbying Congress and the Department of Defense to keep the encryption turned off permanently. Both the American Congress on Surveying and Mapping and the American Geophysical Union (AGU) are also arguing in favour of full civilian access.

At stake for science is mostly the time and money of researchers who now use GPS and of the increasing number of those who are discovering the utility of having a $\$ 3,500$ receiver that can give an absolute global position within five metres. With encryption turned on, real-time measurements degrade to an accuracy of between 30 and 100 metres. Although researchers can use multiple receivers and additional processing of the signals to regain much of the original accuracy, the extra equipment and time can add thousands of dollars to a project.

In the case of ocean floor mapping, where one shipboard receiver gives all the accuracy needed as long as the encryption is off, logistics quickly become a nightmare when it is turned on. To maintain a five-metre accuracy in the face of signal encryption, researchers have to place a second receiver on the closest shore, set up a radio and computer link between the two, and then constantly move the land-based receiver to stay in range.
Christopher Anderson

\title{
Magellan gets set to fill in Venus's gaps
}

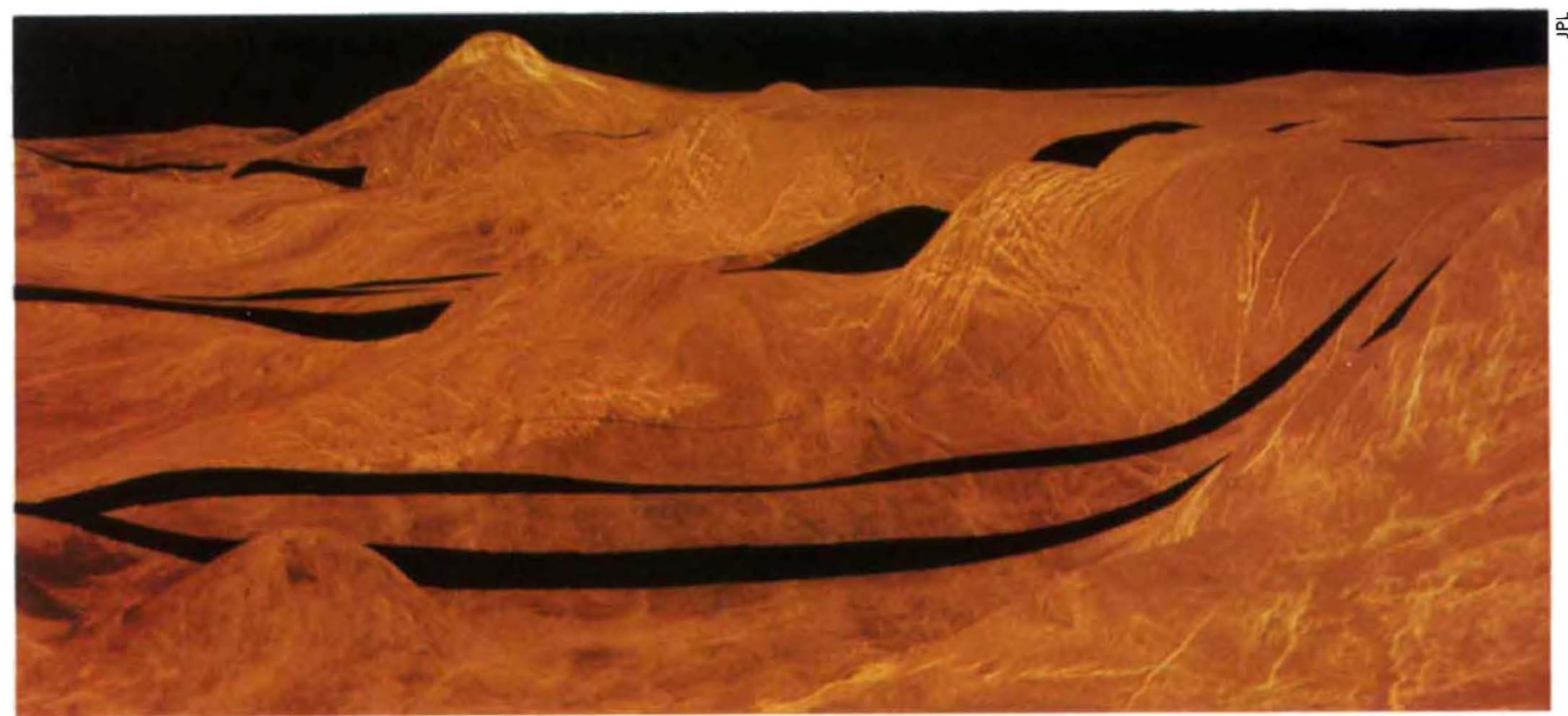

MAGELLAN, NASA's space probe orbitting Venus starts the second cycle of its mission today (16 May). Since 16 August last year, Magellan's $3 \frac{1}{4}$ hour polar orbit has taken it over the whole of the surface of Venus. Eighty two per cent of the surface has now been mapped: some data were lost while Venus was hidden on the far side of the Sun; and mapping of the planet's south pole was impossible owing to the probe's orientation. The picture above shows a three-dimensional perspective view of part of one of Venus's highlands, reconstructed from the orbiter's radar data. Lakshmi Planum, to the right of the image, has an average elevation of 2.5 to $4 \mathrm{~km}$; the mountain to the rear, Danu Montes, rises a further $1.5 \mathrm{~km}$. The gaps in Magellan's coverage, seen above as simple black strips, should be filled in during the probe's second 243-day cycle. A change in the probe's orientation (looking eastwards rather than westwards) will enable it to map the southern pole. One aim is to find evidence of change in regions identified as geologically active during the first pass. 